\title{
Prostacyclin concentrations in haemolytic uraemic syndrome after acute shigellosis in children
}

\author{
A N Alam, N M Abdal, M A Wahed, B Rao, C A Kawser, M Hoque, M M Rahaman
}

\begin{abstract}
The role of prostacyclin in the pathogenesis of haemolytic uraemic syndrome was evaluated in 11 children with acute shigellosis. Plasma concentrations of 6-keto prostaglandin, $F_{1 \alpha}$, a stable metabolite of prostacyclin, were measured by radioimmunoassay during acute illness, early convalescence, and after clinical recovery. Its concentration was low during acute illness in each patient, returning to normal concentrations or above at the time of the last sample. These results suggest that plasma prostacyclin may be involved in the development of the syndrome.
\end{abstract}

Haemolytic uraemic syndrome (HUS) is one of the most important causes of acute renal failure in childhood in some regions of the world. ${ }^{1}$ The association of severe shigellosis with HUS has been well established, ${ }^{2}$ but the pathogenesis of HUS remains unclear. Deficiency of prostacyclin has been implicated in the pathogenesis of the syndrome..$^{4-10}$ Prostacyclin infusion has also been used in the treatment of HUS either with improvement ${ }^{11}$ or equivocal results. ${ }^{12}$ On the other hand, a recent study in five children with HUS showed that plasma 6-keto prostaglandin $F_{1 \alpha}\left(P G F_{1 \alpha}\right)$, the sole stable degradation product of prostacyclin $\left(\mathrm{PGI}_{2}\right)$, was raised. ${ }^{13}$ The present study was aimed at evaluating the concentrations of prostacyclin by measuring $\mathrm{PGF}_{1 \alpha}$ after severe shigellosis in children during the acute and convalescent stages as well as after clinical recovery.

\section{Patients and methods}

SELECTION OF PATIENTS

The study was designed to allow estimation of $\mathrm{PGF}_{1 \alpha}$ on each patient during the three different stages of the illness: on development of HUS (acute stage), during early convalescence (4-5 days after diagnosis of HUS), and on recovery ( $>15$ days after diagnosis, or when serum creatinine concentrations return to normal). This was considered appropriate as each patient acted as his or her own control after recovery. To determine the normal value of prostacyclin, it was measured in 18 apparently healthy volunteers.

One hundred children between 1 and 10 years of age (median age 6 years) with severe shigellosis (characterised by passage of frank blood in the stool with fever, abdominal pain, and signs of toxaemia) with a mean duration of nine days were screened between April 1985 and March 1986 for the development of HUS as indicated by a fall in packed cell volume, thrombocytopenia, and renal failure. Of these, 11 patients were studied prospectively when they developed leukaemoid reaction (white cell counts of $>50 \times$ $10^{9} / 1$ ), clinical evidence of haemolysis, and oliguria (urinary output of less than $10 \mathrm{ml} / \mathrm{kg}$ / day) despite adequate hydration. Development of microangiopathy was indicated by a sudden drop in the packed cell volume $>10 \%$ drop within the first week of hospitalisation and presence of more than $2 \%$ fragmented red blood cells on peripheral blood smears). Patients with septicaemia and other systemic illnesses were excluded from the study. The study had the approval of the ethics committee of the centre and an informed consent was obtained from the parent or legal guardian before any patient was included in the study.

A finger prick blood sample for a complete blood count and peripheral smear was obtained on admission. Venous blood was collected without stasis for assaying prostacyclin by radioimmunoassay and for coagulation measurements, such as partial thromboplastin time, thrombin time, and prothrombin time using Boehringer coagulation assay kits (Boehringer Mannheim). Blood was also collected for culture, measurement of haptoglobin, and determination of serum protein, electrolyte, and creatinine concentrations. Rectal swab and stool were cultured on admission and the next day on MacConkey's agar and on salmonella-shigella agar for isolation of shigella.

Blood was taken from patients during the acute stage of the illness after hydration, during convalescence, and on recovery. On each occasion $4 \mathrm{ml}$ was collected using an ice cold syringe and was transferred into two tubes containing EDTA $(0.7 \mathrm{mg} / \mathrm{ml}$ plasma). One tube was centrifuged at $1500 \mathrm{~g}$ for 15 minutes at $0^{\circ} \mathrm{C}$ to obtain platelet-poor plasma and the other tube was centrifuged at $150 \mathrm{~g}$ to collect platelet-rich plasma. Both samples were then stored at $-20^{\circ} \mathrm{C}$ for subsequent determination of prostacyclin stimulating activity in the plasma samples.

$\mathrm{PGI}_{2}$ production was measured by the method of Moncada et al. ${ }^{14}$ This consisted of cutting fresh rabbit aorta into fine rings, kept in tris buffer $(0.05 \mathrm{M} \mathrm{pH} \mathrm{7.5)}$ on ice for not more than two hours. The rings were then incubated in tris buffer at $22^{\circ} \mathrm{C}$ for five minutes and washed in ice cold buffer. This step was repeated five times to remove the basal prostacyclin activity. Then, $75 \mu \mathrm{l}$ of plateletpoor plasma in $200 \mathrm{ml}$ of buffer were incubated with 40 to $60 \mathrm{mg}$ of the clear vascular tissue at $37^{\circ} \mathrm{C}$ for 15 minutes. At the end of the incubation,
Correspondence to:

Dr Alam.

Accepted 30 May 199 


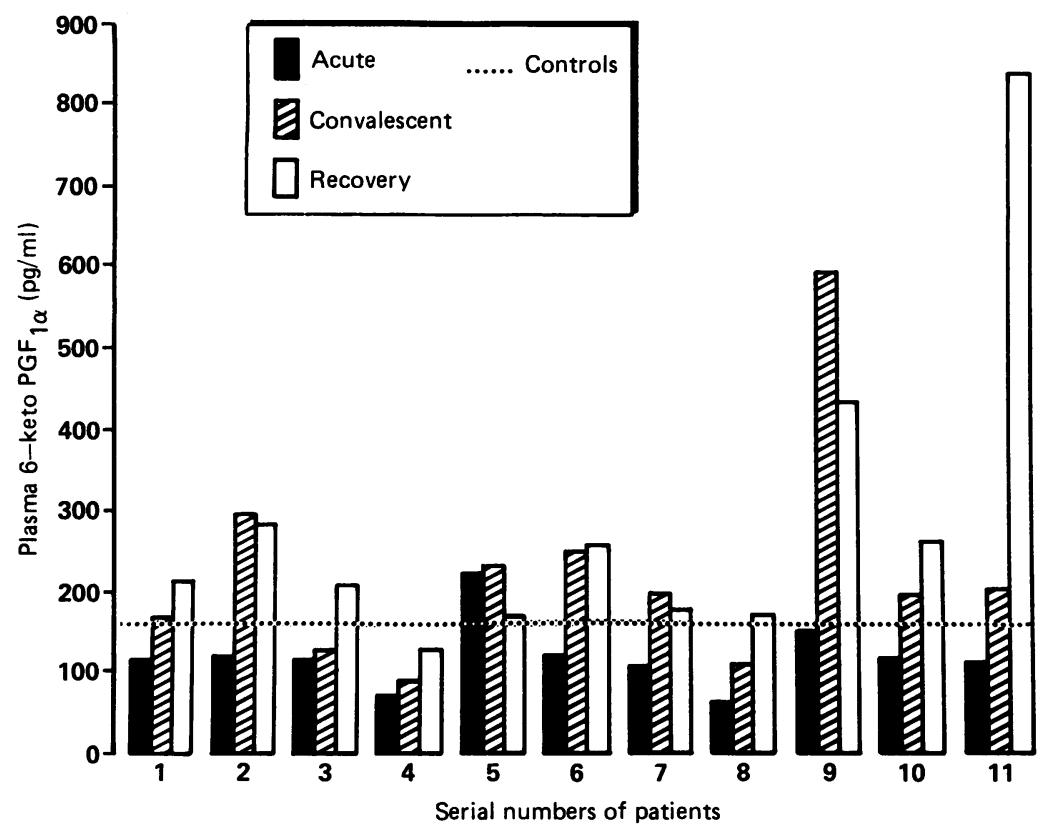

The plasma concentrations of $P G F_{l a}$ for the 11 patients measured during the acute stage of illness, during convalescence, and on recovery, compared with concentrations from healthy controls. activity in the radioimmunoassay of the incubation mixture.

6-keto $\mathrm{PGF}_{1 \alpha}$ concentrations were measured on three occasions in 11 children who had developed HUS after shigellosis—during acute illness, during early convalescence, and on clinical recovery.

Plasma haptoglobin was estimated by haemoglobin binding and gel filtration in seven of the 11 patients during the acute stage of the illness and after clinical recovery.

Antibiotic treatment, fresh blood transfusion, and early institution of peritoneal dialysis, as indicated by raised serum creatinine concentrations, were the standard regimen followed for our patients with HUS.

\section{STATISTICAL ANALYSIS}

Student's $t$ test was used to measure the difference of the means between controls and patients at the acute stage.

\section{Results}

Table 1 shows the clinical characteristics of 11 patients recruited for the study. All patients yielded shigella (Shigella dysenteriae 1 in nine and Shigella flexneri in two). All patients in this study group made complete recovery except one (case 5) who developed chronic renal failure and was lost to follow up after about a year.

Relevant initial laboratory findings in the patients are shown in table 2. All patients had hyponatraemia, hypoalbuminaemia, and raised concentrations of serum creatinine.

Plasma concentration of 6-keto $\mathrm{PGF}_{1 \alpha}$, a stable metabolite of prostacyclin, is shown in the figure. At the peak of the acute stage of the illness the mean (SD) value of $\mathrm{PGF}_{1 \alpha}$ was 135.6 $(41.5) \mathrm{pg} / \mathrm{ml}$. The corresponding value in 18 healthy volunteers was $164 \cdot 1(29 \cdot 2) \mathrm{pg} / \mathrm{ml}$. This difference between the normal control and patients at the acute stage was significant $(p<0.03)$. The value became higher during the two subsequent sampling periods, returning to normal on recovery. Case 4 did not attain the expected normal concentration of $\mathrm{PGF}_{1 \alpha}$ even at the recovery stage. The period of observation was relatively shorter in this patient than in other cases.

Results of the coagulation studies are shown in table 3. In seven of nine patients studied, prothrombin time, thrombin time, and partial

Table 2 Initial laboratory findings of study patients with HUS

\begin{tabular}{|c|c|c|c|c|c|c|}
\hline \multirow{2}{*}{$\begin{array}{l}\text { Case } \\
\text { No }\end{array}$} & \multicolumn{3}{|l|}{ Blood } & \multicolumn{3}{|l|}{ Serum } \\
\hline & $\begin{array}{l}\text { Packed cell } \\
\text { volume }\end{array}$ & $\begin{array}{l}\text { Total white } \\
\text { cell count } \\
\left(\times 10^{9} / l\right)\end{array}$ & $\begin{array}{l}\text { Platelet } \\
\text { count } \\
\left(\times 10^{9} / l\right)\end{array}$ & $\underset{(\mathrm{g} / \mathrm{l})}{\text { Albumin }}$ & $\begin{array}{l}\text { Sodium } \\
(\text { mmolll })\end{array}$ & $\begin{array}{l}\text { Creatinine } \\
(\mu \mathrm{mol} / \mathrm{l})\end{array}$ \\
\hline $\begin{array}{c}1 \\
2 \\
3 \\
4 \\
5 \\
6 \\
7 \\
8 \\
9 \\
10 \\
11 \\
\text { Mean }\end{array}$ & $\begin{array}{l}0 \cdot 30 \\
0 \cdot 20 \\
0 \cdot 25 \\
0 \cdot 28 \\
0 \cdot 30 \\
0 \cdot 31 \\
0 \cdot 26 \\
0 \cdot 29 \\
0 \cdot 29 \\
0 \cdot 16 \\
0 \cdot 26 \\
0 \cdot 26\end{array}$ & $\begin{array}{l}67 \cdot 5 \\
70 \cdot 0 \\
59 \cdot 0 \\
50 \cdot 0 \\
60 \cdot 0 \\
61 \cdot 6 \\
55 \cdot 7 \\
60 \cdot 0 \\
69 \cdot 0 \\
84 \cdot 0 \\
65 \cdot 0 \\
63 \cdot 7\end{array}$ & $\begin{array}{r}25 \\
110 \\
50 \\
120 \\
35 \\
115 \\
130 \\
50 \\
55 \\
70 \\
100 \\
80.0\end{array}$ & $\begin{array}{l}30 \\
32 \\
28 \\
30 \\
32 \\
25 \\
34 \\
26 \\
30 \\
32 \\
26 \\
30.3\end{array}$ & $\begin{array}{l}124 \\
124 \\
123 \\
130 \\
130 \\
124 \\
124 \\
124 \\
102 \\
125 \\
119 \\
122 \cdot 6\end{array}$ & $\begin{array}{l}249 \\
513 \\
282 \\
287 \\
498 \\
311 \\
539 \\
462 \\
700 \\
290 \\
678 \\
428\end{array}$ \\
\hline
\end{tabular}


Table 3 Coagulation abnormalities in patients on development of HUS

\begin{tabular}{llll}
\hline $\begin{array}{l}\text { Case } \\
\text { No }\end{array}$ & $\begin{array}{l}\text { Prothrombin } \\
\text { time } \\
(s)\end{array}$ & $\begin{array}{l}\text { Partial } \\
\text { thromboplastin } \\
\text { time } \\
(s)\end{array}$ & $\begin{array}{l}\text { Thrombin } \\
\text { time } \\
(s)\end{array}$ \\
\hline 1 & $16(12)$ & $30(25)$ & $22(18)$ \\
2 & $17(12)$ & $32(28)$ & $25(20)$ \\
3 & $22(15)$ & $25(28)$ & $22(18)$ \\
4 & $11(12)$ & $20(20)$ & $19(18)$ \\
5 & $15(11)$ & $30(26)$ & $24(20)$ \\
6 & $15(11)$ & $25(20)$ & $24(18)$ \\
7 & $15(14)$ & $25(21)$ & $17(16)$ \\
8 & - & - & - \\
9 & - & $31(25)$ & $22(18)$ \\
10 & $16(12)$ & $30(25)$ & $24(18)$ \\
11 & $16(12)$ & & \\
\hline
\end{tabular}

Control values in parenthesis.

Table 4 Serum haptoglobin concentrations $(\mathrm{mg} / 100 \mathrm{ml})$ in patients with HUS

\begin{tabular}{lccc}
\hline & $\begin{array}{c}\text { Acute } \\
(n=7)\end{array}$ & $\begin{array}{c}\text { Recovery } \\
(n=7)\end{array}$ & $\begin{array}{c}\text { Mean } \\
\text { difference }\end{array}$ \\
\hline Mean & $65 \cdot 4$ & $212 \cdot 3$ & $146 \cdot 9^{*}$ \\
SEM & $7 \cdot 6$ & $32 \cdot 2$ & $30 \cdot 1$ \\
\hline${ }^{*} \mathrm{p}<0.002$ (paired $t$ test). & &
\end{tabular}

thromboplastin time were prolonged. Table 4 shows the serum haptoglobin concentrations in seven of the patients who were included in the coagulation studies. Significantly low values were observed in the acute stage of the illness which returned to normal after recovery. The mean (SEM) difference between the recovery and the acute stage was $146.9(30 \cdot 1)$. Although the value in the acute stage was significantly lower $(p<0.001)$ than the healthy controls with a mean (SE) of $183.5(5 \cdot 2)$, the difference between the values from controls and patients on recovery was not significant.

\section{Discussion}

The study clearly showed an overall depression of $\mathrm{PGF}_{1 \alpha}$ concentrations in patients with HUS during the early phase of the illness which subsequently increased to normal values during early convalescence and on recovery. To our knowledge this is the first reported longitudinal study which measured the concentrations of a prostacycylin metabolite in HUS where the patient acted as his own control. Moreover, the patients in the study were clinically a distinct group in that all had severe shigellosis as the primary illness. HUS after severe dysentery has been reported from the Indian subcontinent since $1975 .^{2}{ }^{115}$ It seems that during each cycle of a shigellosis epidemic, a fresh crop of patients with HUS are seen.

It is difficult to offer an explanation for these low values of $\mathrm{PGF}_{1 \alpha}$ during the early phase of HUS in the absence of other prostaglandin metabolites, such as thromboxane $A_{2}$. Perhaps this low concentration indicates either a high rate of consumption of prostacyclin or poor production. In all cases, after clinical recovery, the prostacyclin concentrations increased significantly, often exceeding those found in the apparently healthy volunteers. Hence, as suggested earlier, ${ }^{45}$ the development of HUS may be a response to the lack of a plasma factor that stimulates prostacyclin activity during the acute stage.
Prostacyclin, a potent vasodilator and inhibitor of platelet aggregation, is produced by the endothelial tissue of the vascular system. It has now been established that endothelial damage is caused by endotoxin, due to Gram negative bacteraemia, a common finding in severe shigellosis, particularly when due to $S d y s-$ enteriae type $1 .^{3}$ The observed initial lowering of prostacyclin is probably due to its high consumption and/or low production because of the damaged endothelial lining. Subsequent increase is probably due to recovery of the vascular endothelium after clearance of the endotoxin from the circulation.

The changes observed in the coagulation parameters could either be due to the presence of fibrinogen-fibrin degradation products or deficiency of fibrinogen. We could not do fibrinogen-fibrin degradation product measurements in this study. However, mildly abnormal clotting studies in the presence of appreciable thrombocytopenia are compatible with disseminated intravascular coagulation which is commonly associated with HUS. Intravascular haemolysis, as evidenced by significantly decreased values for haptoglobin, was marked only in the acute stage of the illness.

Other laboratory evidence indicates that all these patients made apparently complete recovery from this with the exception of one who developed chronic renal failure.

In this study we could not include patients with acute shigellosis without HUS to act as controls. This would have helped us in understanding whether depression of prostacyclin is a matter of degree or an 'all or none' phenomenon.

HUS is probably not a single disease entity and it is more likely that different pathogenetic mechanisms may underlie different forms of the disease. Levin et al found reduced prostacyclin production in children with a sporadic type of HUS, which they thought to be due to the presence of an inhibitory substance. ${ }^{10}$ It would be difficult to classify our patients as clearly sporadic or epidemic. All the study children, however, initially had acute shigellosis and most had clinical characteristics of both types.

Our data support the view that in the acute stage of post-shigellosis HUS, lowering of $\mathrm{PGF}_{1 \alpha}$ concentrations may have an important role in the pathophysiology of HUS, although endotoxaemia may yet prove to be a precipitating factor in the HUS which develops after shigellosis.

The International Centre for Diarrhoeal Disease Research, Bangladesh (ICDDR,B) is supported by countries and agencies which share its concern about the impact of diarrhoeal diseases on the developing world. Current major donors giving assistance on the developing world. Current major donors giving assistance to ICDDR,B are: The Aga Khan Foundation, Arab Gulf Fund,
Australia, Bangladesh, Belgium, CIDA, IRDC, DANIDA, Fustralia, Bangladesh, Belgium, CIDA, IRDC, DANIDA, France, The Ford Foundation, Japan, The Netherlands, UNICEF, UNCDF, USAID, WHO, and WUSC

We sincerely thank Mr Meer Md Ramzan Ali for secretarial work and Dr Bogdan Wojtyniak for his kind assistance in statistical analyses.

1 Gianantonio C, Vitacco M, Mendilaharzu F, et al. The hemolytic uremic syndrome. F Pediatr 1964;64:478-91.

2 Rahaman MM, Alam AKMJ, Islam MR, Greenough III WB, Lindenbaum J. Shiga bacillus dysentery associated with marked leukocytosis and erythrocyte fragmentation. Fohns Hopkins Med F 1975;136:65.

3 Koster F, Levin J, Walker L, et al. Hemolytic uremic syndrome after shigellosis. $N$ Engl f Med 1978;298:927. 
4 Remuzzi G, Marchesi D, Mecca G, et al. Haemolytic uremic syndrome: deficiency of plasma factor(s) regulating prostacyclin activity? Lancet 1978;ii:871.

5 Webster J, Rees AJ, Lewis PJ, Hensby CN. Prostacyclin deficiency in haemolytic-uraemic syndrome. $B M \mathcal{Y} 1980$; 281:271.

6 Jorgensen KA, Pedersen RS. Familial deficiency of prostacyclin production stimulating factor in the hemolytic uremic syndrome of childhood. Thromb Res 1981;21:311-6.

7 Chamone DAF, Proesmans. WC, Monnens LA, Binda KI, Muaka P, Vermylen J. Reversible deficient prostacyclin release in childhood hemolytic uremic syndrome. Int I Pediatr Nephrol 1982;3:13-6.

8 Turi S, Beattie TJ, Belch JJF, Murphy AV. Disturbances of prostacyclin metabolism in children with hemolytic uremic syndrome and in first degree relatives. Clin Nephrol 1986; 25:193-8.

9 Wiles PG, Solomon LR, Lawer W, Mallick NP. Inherited plasma factor deficiency in haemolytic uraemic syndrome. Lancet 1981;i:1105-6.

10 Levin M, Elkon KB, Nokes JC, et al. Inhibitor of prostacyclin production in sporadic haemolytic uraemic syndrome. Arch Dis Child 1983;58:703-8.

11 Beattie TJ, Murphy AV, Willoughby MLN, Belch JJF. Prostacyclin infusion in haemolytic-uremic syndrome of children. $B M \mathcal{F}$ 1981;283:470

12 Defreyn G, Proesmans WC, Machin SJ, Lemmens F, Vermylen J. Abnormal prostacyclin metabolism in the hemolytic uremic syndrome: equivocal effect of prostacyclin infusion. Clin Nephrol 1982;18:43-9.

13 Stuart MJ, Spitzer RE, Walenga RW, Boone S. Prostanoids in hemolytic uremic syndrome 7 Pediatr 1985;106:936-9.

4 Moncada S, Higgs EA, Vane JR Human arterial and venous tissues generate prostaglandin (prostaglandin $\alpha$ ), a potent tissues generate prostaglandin (prostaglandin $\alpha$ ), a pot
inhibitor of platelet aggregation. Lancet 1977; i:18-21.

15 Raghupathy P, Data A, Shastry JCM, et al. Haemolyticuraemic syndrome complicating shigella dysentery in south uraemic syndrome complicating shigel

Lisch nodules

These nodules on the iris were first described by Waardenburg in 1918 but Lisch pointed out their association with von Recklinghausen's neurofibromatosis in 1937. They are small, clear, yellow or brown nodules which project from the surface of the iris and when multiple are thought to be diagnostic of neurofibromatosis. In pathological terms they are melanocytic harmartomas. They can be seen with the naked eye but are best observed and distinguished from naevi on the iris by slit lamp examination. Guidelines for the diagnosis of neurofibromatosis were offered at a consensus conference in 1987..$^{1}$ There are two types. Peripheral neurofibromatosis, or von Recklinghausen's disease, is type 1 and type 2 is central neurofibromatosis associated with bilateral acoustic neuromas. Lisch nodules are associated with type 1 disease which may be diagnosed in the presence of two or more of: two or more neurofibromas, one plexiform neurofibroma, axillary or inguinal freckling, optic glioma, two or more Lisch nodules, a typical lesion of bone, or an affected first degree relative.

A recent report from Miami Children's Hospital (Marie-Louise E Lubs and colleagues, New England Fournal of Medicine 1991; 324:1264-6) examines the significance of Lisch nodules in 167 patients from 120 families with type 1 neurofibromatosis. Under the age of 3 years both Lisch nodules and neurofibromas were uncommon being found in only 5 and $10 \%$ of patients respectively. Thereafter the prevalence of both features increased steadily throughout childhood with Lisch nodules being the more common feature at all ages. They were found in $42 \%$ of 3 or 4 year olds, about $80 \%$ of 9 to 14 year olds, and in all 65 adults over the age of 20 years. Neurofibromas were present in $10 \%$ of 3 or 4 year olds, $50 \%$ of 9 to 14 year olds, and $95 \%$ of adults. Lisch nodules were never the only finding, there were always other signs of the disease, usually café au lait spots. The prevalence of the nodules was not influenced by the clinical severity of the disease, race, sex, family history, or the presence or absence of central nervous system tumours.

The absence of Lisch nodules virtually excludes the presence of the neurofibromatosis gene in an adult. In children with only one of the diagnostic criteria the diagnosis becomes less likely with increasing age in the continued absence of the nodules. The authors calculate that in such circumstances the risk of having the gene is $50 \%$ at birth, $15 \%$ at 9 to 14 years, and zero over the age of 20 years. 